\title{
Surface Plastic Deformation and Nanocrystallization Mechanism of Welded Joint of 16MnR Steel Treated by Ultrasonic Impact
}

\author{
Yingxia YU ${ }^{1}$, Bolin $\mathrm{HE}^{1}{ }^{*}$, Jing LIU $^{2}$, Zhaoxia CHEN ${ }^{1}$, Hua MAN ${ }^{1}$ \\ ${ }^{1}$ Key Laboratory of Ministry of Education for Conveyance and Equipment, East China Jiaotong University, Nanchang \\ 330013, China \\ ${ }^{2}$ Jiangling Motors Corporation, Ltd, Nanchang 330001, China

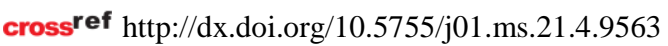

Received 23 January 2015; accepted 03 October 2015

\begin{abstract}
The welded joint surfaces of $16 \mathrm{MnR}$ steel were treated using an ultrasonic impact machine. The effects of ultrasonic impact treating (UIT) on the plastic deformation and nanocrystallization mechanism of the welded joints of $16 \mathrm{MnR}$ steel were studied. The micro-structural features of the surface layer produced by UIT were observed by scanning electron microscopy (SEM) and high resolution transmission electron microscopy (HRTEM), and micro-hardness measurements were performed. Experimental results showed that the thickness of the plastic deformation layer was approximately 80 $\mu \mathrm{m}$. It was found that grains in the surfaces of the welded joints of $16 \mathrm{MnR}$ were greatly refined by UIT. Obvious grain refinement was observed, with resultant gain sizes less than $100 \mathrm{~nm}$. The micro-hardness of the treated surface layer of the welded joint was enhanced significantly compared to that of the un-treated sample. The micro-hardness on the treated surface of the welded joint was $62.3 \%$ higher than that of the un-treated surface.

Keywords: nanocrystallization, mechanism, $16 \mathrm{MnR}$ steel, ultrasonic impact, welded joint.
\end{abstract}

\section{INTRODUCTION}

$16 \mathrm{MnR}$ steel is one of the most widely used materials in mechanical manufacturing, especially in pressure vessel and train bogies, due to its high strength and weldability. As a primary part of a train, bogies carry static loads due to their weight, and bear dynamic loads due to rail surface roughness and imperfect wheels. Bogie frames are continuously subjected to various dynamic loads, and consequently, fatigue phenomena. With increasing train speed, the dynamic loads on welded bogie frames also increase. Welding is the basic connection process of train bogies; it would lead to residual stress in the weld area. The fatigue strength of a welded joint is lower due to the stress concentration in the weld toe, thus becoming the weak link in the carrying capacity of a bogie. Fatigue properties affect the life span of a bogie and the travelling crane safety of the vehicles $[1,2]$. There is an increasing number of serious railway transportation accidents caused by structural fatigue of bogies $[3,4]$. Surface nanocrystalline technology can refine the grains in metal surfaces on the nano-level without changing the chemical compositions. As a result, surface properties such as fatigue strength, corrosion resistance, and abrasion resistance are improved [5-9]. In recent years, attempts are made to refine the surface grains using surface nanocrystallization processes [10-13].

Ultrasonic impact treating (UIT) is a recentlydeveloped technique that can refine surface layer grains of bulk materials. Surface nanocrystallization is expected to afford a new approach for the application of nanostructured materials, and has already been successfully applied in surface grain refinement of a variety of materials including pure metals, alloys and welded joints [14-18].

\footnotetext{
Corresponding author. Tel.: +86-0791-87046116; fax: +86-079187046122. E-mail address: hebolin@163.com (B. He)
}

Although the method has been developed for actual application, there is little research about the surface grain refinement of welded joints of $16 \mathrm{MnR}$ steel using UIT. In this study, the effects of UIT on the plastic deformation and nanocrystallization mechanism of welded joints of $16 \mathrm{MnR}$ steel was discussed, and the micro-hardness was also studied.

\section{EXPERIMENTAL}

\subsection{Materials}

The test material was $16 \mathrm{MnR}$ steel, which is frequently used in bogie structures. The chemical composition and mechanical properties are shown in Table 1 and Table 2 .

Table 1. Chemical composition of $16 \mathrm{MnR}$ steel (wt.\%)

\begin{tabular}{|c|c|c|c|c|c|c|c|}
\hline $\mathrm{C}$ & $\mathrm{Mn}$ & $\mathrm{Si}$ & $\mathrm{S}$ & $\mathrm{P}$ & $\mathrm{Ni}$ & $\mathrm{Cr}$ & $\mathrm{Ti}$ \\
\hline 0.14 & 1.32 & 0.27 & 0.004 & 0.012 & 0.07 & 0.06 & 0.018 \\
\hline
\end{tabular}

Table 2. General mechanical properties of $16 \mathrm{MnR}$ steel

\begin{tabular}{|c|c|c|c|c|c|}
\hline$E, \mathrm{MPa}$ & $\sigma_{\mathrm{s}}, \mathrm{MPa}$ & $\sigma_{\mathrm{b}}, \mathrm{MPa}$ & $\delta, \%$ & $v$ & $\Psi, \%$ \\
\hline $2.1 \times 10^{5}$ & 366 & 580 & 27 & 0.28 & 58 \\
\hline
\end{tabular}

\subsection{Preparation of the specimen}

The joints were welded after straightening and correcting of distortion. Further details regarding the preparation of the specimen can be found in reference [19]. The weld inspections found that except for one or two specimens with slight distortions, most of the specimens appeared well-aligned. The circular fillets of all the specimens were grinded smooth, in order to prevent fractures in the transitions. The UIT equipment (made by SUNBOW, China) consisted of an ultrasonic generator with a frequency of approximately $20 \mathrm{kHz}$ and an output power of about $1.0 \mathrm{~kW}$, a piezo-ceramic transducer, step- 
like ultrasonic horn made from high strength material, and an impact head installed on the horn tip. The impact head contained cylindrical pins which were able to move freely between the horn tip and the treated surface. The single-pin diameter was $8 \mathrm{~mm}$, and multiple pins arranged side by side had diameters of $3 \mathrm{~mm}$. The UIT equipment is comprised of a handheld tool and an electronic control box containing an ultrasonic generator. The tool is easy to operate and provide a better comfortable work environment with negligible noise and vibration.

\subsection{Microstructure observation and hardness test}

The microstructure of the sample's cross-section was examined after UIT using a SJM-6360LA scanning electron microscope (JEOL, Japan). The average grain size was measured in terms of the scale line. The microstructure of the treated surface layer was observed using a JEM-2010 high resolution transmission electron microscope (JEOL, Japan). The micro-hardness of the nanocrystalline surface layer was measured using a XHV$1000 \mathrm{Z}$ Vicker's hardness tester with a load of $100 \mathrm{~g}$ and duration of $10 \mathrm{~s}$.

\section{RESULTS AND DISCUSSION}

Fig. 1 shows a cross-sectional SEM image of the sample after UIT. Obviously, the microstructure morphology of the treated surface layer is quite different from that in the matrix. Evidences of severe plastic deformation are seen in the surface layer, in which grain boundaries cannot be clearly identified as can be seen in the matrix. The thickness of the plastic deformation layer was approximately $80 \mu \mathrm{m}$, and was not uniform, indicating the heterogeneity of plastic deformation induced by this treatment method.

In order to analyze the microstructure of the specimen after the UIT process, a JEM-2100 high resolution transmission electron microscope (HRTEM) was used. Fig. 2 a shows a bright-field image, Fig. 2 b shows a dark field image, and the corresponding selected area electron diffraction (SAED) pattern of the top surface layer in the surface of the welded joint of $16 \mathrm{MnR}$ steel after UIT is shown in the center. It was clear that the microstructure was characterized by ultrafine equiaxed grains with random crystallographic orientations, as indicated by the SAED pattern. The average grain size of the top layer was less than $100 \mathrm{~nm}$ and the grains at the top surface were uniform. The experimental results clearly demonstrated that nanostructures were developed in the surface layer of the welded joint of the $16 \mathrm{MnR}$ steel during UIT.

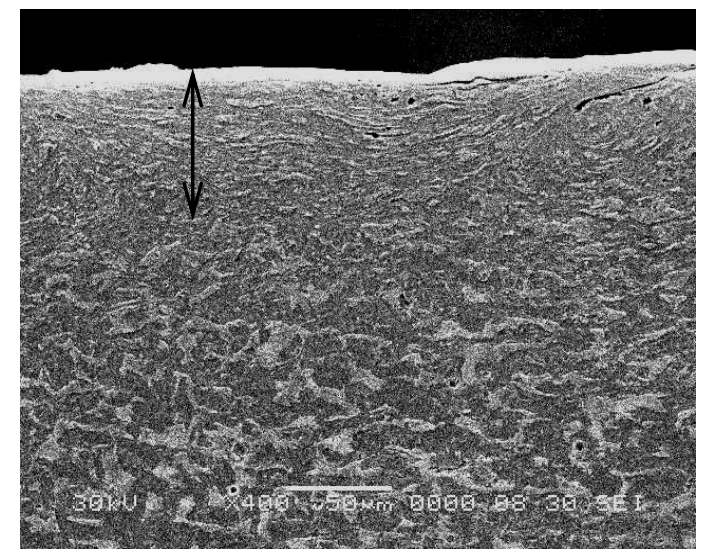

Fig. 1. Observation of the cross section after UIT

The Vickers hardness on the surface of the treated and un-treated welded joint was measured by a XHV-1000Z micro-hardness tester while applying a $100 \mathrm{~g}$ load for $10 \mathrm{~s}$. The hardness results for the treated and un-treated surface of the welded joint was 297 and 183, respectively. The hardness on the treated surface was $62.3 \%$ higher than that of the un-treated surface of the welded joint of $16 \mathrm{MnR}$ steel. The increase in the hardness after UIT can be attributed to both grain refinement and the work-hardening effect on the surface layer due to the Hall-Petch relationship [8], which provides an empirical description of grain boundary strengthening in many metals and alloys. It is expressed as [20]:

$H=H_{0}+K d^{-1 / 2}$,

where $K$ is a constant for a given material, $H_{0}$ is an appropriate constant associated with the hardness measurements and $d$ is the mean grain size. This relationship has been confirmed in both theory and practice in many metallic materials with grain size in the micrometer scale.

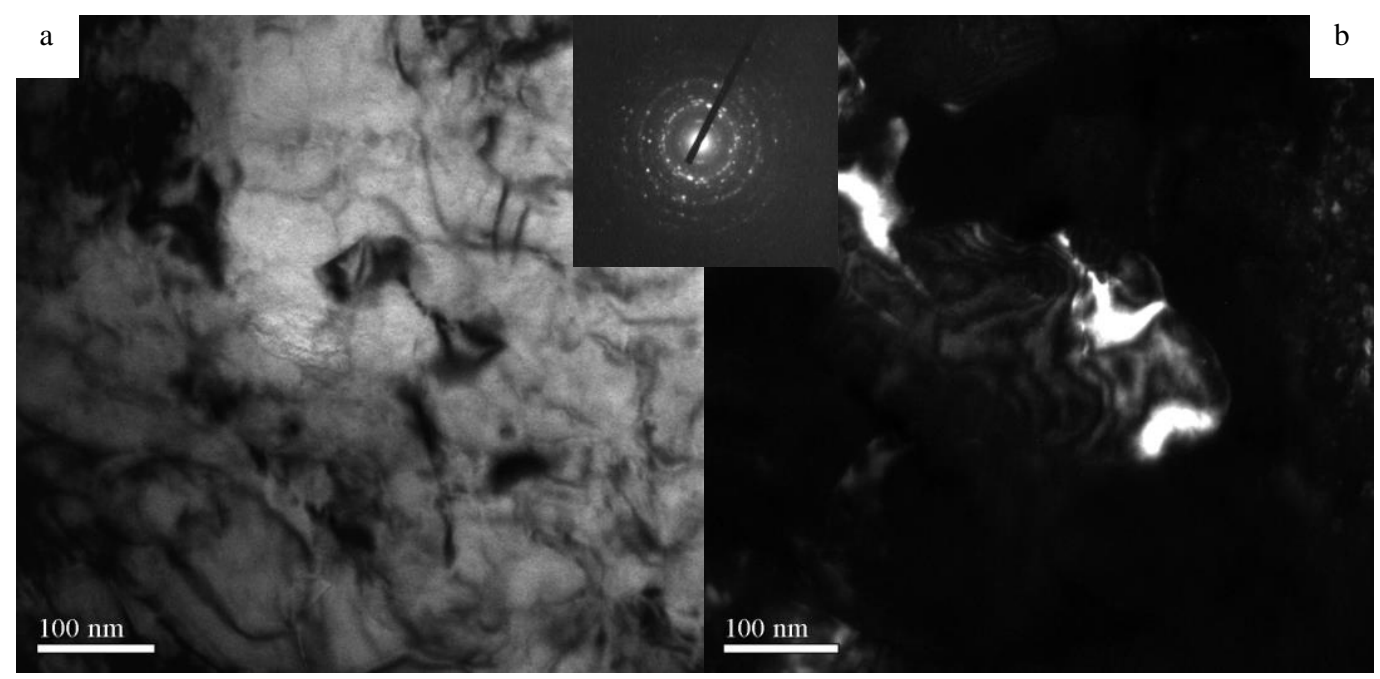

Fig. 2. a-bright field image; b-dark field image and the corresponding SAED pattern in the middle 
Generally speaking, the pattern of plastic deformation which includes dislocation and twinning is dependent on the stacking fault energy of the materials. For the materials with high stacking fault energy, the main pattern of plastic deformation is dislocation slip. Alternately, for materials with low stacking fault energy, the main pattern of plastic deformation is twinning. Because $16 \mathrm{MnR}$ is a material with a high stacking fault energy, its plastic deformation pattern is dislocation slip [21]. The grain refinement process on the treated surface of the $16 \mathrm{MnR}$ steel welded joint is shown in Fig. 3 [22].

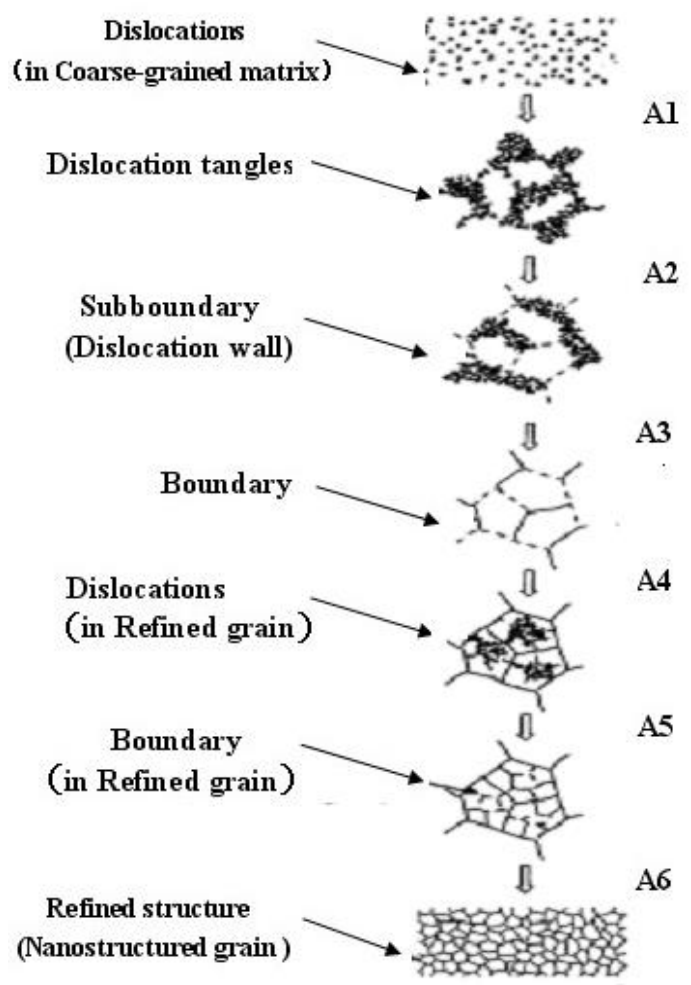

Fig. 3. Sketch map of the mechanism of refining grains by UIT [22]

During the UIT process, dislocation are appeared and moved in the coarse grain matrix (see Fig. 3 (A1)). Because $16 \mathrm{MnR}$ has a high stacking fault energy, the dislocations did not distribute uniformly after plastic deformation, showing high dislocation density regions and low dislocation density regions. With an increase in the ultrasonic impact time, dislocation tangles were formed, as can be seen in Fig. 3 (A2). The dislocation density increased with increase in deformation. When dislocation slip continued to occur, intersections among the dislocations were commonplace and a different type of dislocation pattern emerged. The dislocation tangles transformed into cellular structures, as is shown in Fig. 4, in the surface of the welded joint of $16 \mathrm{MnR}$ steel. The cell structure consisted of boundaries in which dislocations were preferentially stored and the cell interiors were relatively dislocation free. With an increase of plastic deformation, dislocations in the cell boundaries interacted and dislocation walls with small angle misorientation were formed. Original coarse grains were divided into small cell structures. In order to decrease the high energy in the boundaries, high density dislocations in the cell boundaries became sub-boundaries with very small angles, and original coarse grains divided into many smaller grains of different sizes, which was carried out by means of annihilation and rearrangement.

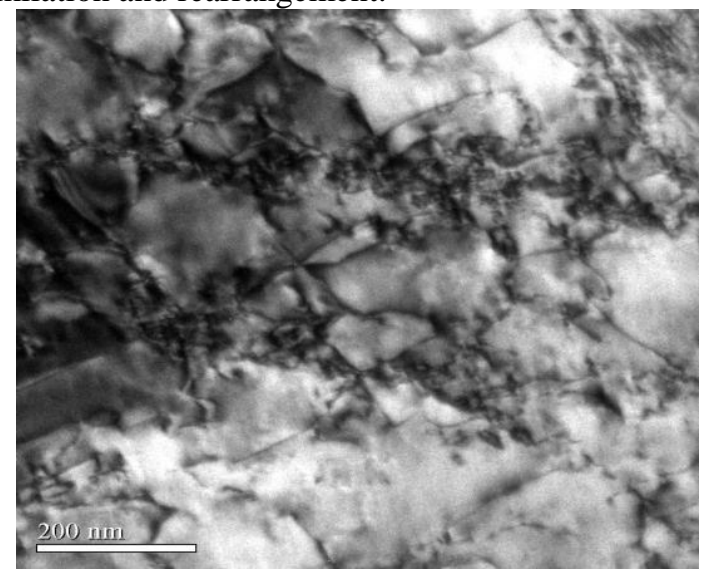

Fig. 4. Cellular structure in deformed joint of $16 \mathrm{MnR}$ steel

With an increase in the UIT time and continued plastic deformation, dislocation tangles and dislocation wall were formed repeatedly in the refined sub-grains. This dislocation arrangement minimized the total strain energy. With continued plastic deformation, a concurrent increase in dislocation density occurred, leading to decreased cell sizes (see Fig. 3 (A4 - A6)). When the annihilating rate of the dislocations was equal to the increasing rate of dislocations, there was dynamic equilibrium. The grain size no longer decreased with an increase in plastic deformation, and was kept stable. The strain rate in the surface of the welded joint of $16 \mathrm{MnR}$ steel was very high during the UIT, and the strain rate decreased dramatically away from the surface. Because both the strain rate and strain in quantity were prodigious and the dislocation density was very high, nano-sized dislocations walls were formed. Compared to the coarse grains, the turning of nano-grains and the slipping of nano-grain boundaries are occurred easily. Equiaxed nano-grains (or nanostructures) with random distribution was found in the surface layer after the ultrasonic impact treating.

The size $(D)$ of the dislocation cells that are formed in the coarse grains has a direct relationship with the applied shear stress $(\tau)$. The empirical relation can be written as [11]:

$D=K G b \tau^{-1}$,

where $K$ is a constant with a value close to ten, $G$ is the shear modulus and $b$ is the slip distance (or Burgers vector). The shear stress $\tau$ decreases as it moves away from the impact surface. In Eq. 2 it can be seen that the closer to the impact surface, the bigger the shear stress $\tau$, and the smaller the size $(D)$ of the dislocation cell is. Nano-sized dislocation cells were obtained in some surface regions. With continued ultrasonic impact treating, and a concurrent increase in dislocation density, new dislocation tangles and walls were formed, which led to many smaller dislocation cell and sub-grain boundaries. The size of the dislocation cells decreased continuously, so nano-grains eventually formed.

\section{CONCLUSIONS}

1. Grain sizes in the surfaces of welded $16 \mathrm{MnR}$ steel joint can be refined greatly by UIT, and a 
nanostructured surface layer was successfully obtained on the surface of a welded $16 \mathrm{MnR}$ joint using the UIT method. The thickness of the plastic deformation layer was approximately $80 \mu \mathrm{m}$ and the grain size was less than $100 \mathrm{~nm}$ in the top surface layer of the welded joint.

2. After UIT, the micro-hardness of the treated surface layer of the welded joint was enhanced significantly compared to that of the un-treated sample. The microhardness on the treated surface of the welded joint was $62.3 \%$ higher than that of the un-treated surface.

3. The procedures of UIT plastic deformation include three steps. Firstly, dislocation entanglements and dislocation walls are formed in the coarse grains. Secondly, when dislocation slip occurs continuously, intersections among the dislocations are commonplace and a different type of dislocation pattern emerges. The dislocation tangles are transformed into cellular structures. And thirdly, with continued UIT process, a concurrent increase in dislocation density, new dislocation tangles and dislocation wall are formed, which lead to many smaller dislocation cells and subgrain boundaries. The size of the dislocation cells decrease continuously, so nano-grains are eventually formed.

\section{Acknowledgement}

The work is supported by the National Nature Science Foundation of China (51365014) and the Nature Science Foundations of Jiangxi Province (20151BAB206007, 2009GZC0016).

\section{REFERENCES}

1. Kim, J.S. Fatigue Assessment of Tilting Bogie Frame For Korean Tilting Train: Analysis and Static Tests Engineering Failure Analysis $13(8) \quad$ 2006: pp. 1326-1337. http://dx.doi.org/10.1016/j.engfailanal.2005.10.007

2. Baek, S.H., Cho, S.S., Joo, W.S. Fatigue Life Prediction Based on The Rainflow Cycle Counting Method for The End Beam Of A Freight Car Bogie International Journal of Automotive Technology 9 (1) 2008: pp. 95-101. http://dx.doi.org/10.1007/s12239-008-0012-y

3. Wu, H.C., Wu, P.B. Bogie Frame Fatigue Simulation Based on Flexible Multibody Dynamics International Conference On Transportation Engineering, Chengdu 2009: pp. $1831-1837$.

4. Zhang, W.H., Wu, P.B., Wu, X.J., Zeng, J. An Investigation Into Structural Failures of Chinese High-Speed Trains Engineering Failure Analysis 13 (4) 2006: pp. 427-435. http://dx.doi.org/10.1016/j.engfailanal.2004.12.037

5. Lu, K., Lu, J. Nanostructured Surface Layer on Metallic Materials Induced by Surface Mechanical Attrition Treatment Material Science and Engineering A 375-377(1) 2004: pp. $38-45$.

6. He, B.L., Liu, J., Wang, B. Study on the Methods of the Surface Self-nanocrystalline Technology and its Effect on the Materials Properties Applied Mechanics and Materials 80-81 (2) 2011: pp. 673-677.

7. Amanov, A., Penkov, O.V., Young, S.P., Dae, E.K. Effects of Ultrasonic Nanocrystalline Surface Modification on The Tribological Properties of AZ91D Magnesium Alloy Tribology International 54 2012: pp. 106-113. http://dx.doi.org/10.1016/j.triboint.2012.04.024

8. Amanova, A., Cho, I.S., Pyouna, Y.S., Lee, C.S., Parkb, I.G. Micro-Dimpled Surface by Ultrasonic Nanocrystal Surface
Modification and Its Tribological Effects Wear 286-287 2012: pp. 136-144.

9. Haghayeghi, R., Ezzatneshan, E., Bahai, H., Nastac, L. Numerical and Experimental Investigation of the Grain Refinement of Liquid Metals through Cavitation Processing Metals and Materials International 19 (5) 2013: pp. 959-967.

http://dx.doi.org/10.1007/s12540-013-5008-0

10. Lu, K., Lu, J. Surface Nanocrystallization(SNS) of Metallic Materials-presentation of the Concept behind a New Approach Journal of Materials Science \& Technology 15 (3) 1999: pp. $193-197$.

11. Zhang, H.W., Liu, G., $\quad$ Hei, Z.K., $\quad$ Lu, K. $\quad$ Surface Nanocrystallization of AISI 304 Stainless Steel Induced by Surface Mechanical Attrition Treatment I. Structure and Property Acta Metallrugica Sinica 39 (4) 2003: pp. 342-346.

12. Prakash, N.A., Gnanamoorthy, R., Kamaraj, M. Surface Nanocrystallization of Aluminium Alloy By Controlled Ball Impact Technique Surface \& Coatings Technology 210 2012: pp. $78-89$. http://dx.doi.org/10.1016/j.surfcoat.2012.08.069

13. Villegas, J.C., Shaw, L.L. Nanocrystallization Process and Mechanism in A Nickel Alloy Subjected To Surface Severe Plastic Deformation Acta Materialia 57 (19) 2009: pp. $5782-5795$. http://dx.doi.org/10.1016/j.actamat.2009.08.005

14. He, B.L., Yu, Y.X., Yu, H.H., Jiang, M.H., Shi, J.P. Effect of Ultrasonic Impact on The Surface Microstructure And Fatigue Properties of Welded Cross Joint for Train Bogie Transaction of the China Welding Institution 34 (8) 2013: pp. 51-54.

15. Yin, D.Q., Wang, D.P., Jing, H.Y., Huo, L.X. The Effects of Ultrasonic Peening Treatment on The Ultra-Long Life Fatigue Behaviour of Welded Joints Materials and Design 31(7) 2010: pp. 3299-3307. http://dx.doi.org/10.1016/j.matdes.2010.02.006

16. Zhao, X.H., Wang, D.P., Huo, L.X. Analysis of The S-N Curves of Welded Joints Enhanced by Ultrasonic Peening Treatment Materials and Design 32 (1) 2011: pp. 88-96. http://dx.doi.org/10.1016/j.matdes.2010.06.030

17. Yan, W.L., Fang, L., Zheng, Z.G., Sun, K., Xu, Y.H. Effect of Surface Nanocrystallization on Abrasive Wear Properties in Hadfield Steel Tribology International 42 (5) 2009: pp. 634-641. http://dx.doi.org/10.1016/j.triboint.2008.08.012

18. Yekta, R. T., Ghahremani, K., Walbridge, S. Effect of Quality Control Parameter Variations on The Fatigue Performance of Ultrasonic Impact Treated Welds International Journal of Fatigue 55 2013: pp. 245-256. http://dx.doi.org/10.1016/j.ijfatigue.2013.06.023

19. He, B.L., Yu, Y.X., Shi, J.P., Yu, H.H. The Effect of Ultrasonic Impact on The Fatigue Properties of $16 \mathrm{MnR}$ Steel Welded Joints for Bogie China Railway Science 32 (5) 2011: pp. 96-99.

20. Zherebtsov, S., Salishchev, G., Galeyev, R., Maekawa, K. Mechanical properties of Ti-6Al-4V titanium alloy with submicrocrystalline structure produced by severe plastic deformation Materials Transactions $46(9)$ 2005: pp. $2020-2025$. http://dx.doi.org/10.2320/matertrans.46.2020

21. Valiev, R.Z., Islmagaliev, R.K., Alexnadrov, I.V. Bulk Nanostructured Materials from Severe Plastic Deformation Progress in Materials Science 45 (2) 2000: pp. 103-189. http://dx.doi.org/10.1016/S0079-6425(99)00007-9

22. Liu, J. Study on the Mechanism of $16 \mathrm{MnR}$ Ultrasound Impacting Surface Nanocrystallization, Master thesis, East China Jiaotong University, Nanchang, 2011 (in Chinese). 